\title{
CtBP2 interacts with TGIF to promote the progression of esophageal squamous cell cancer through the Wnt/ $\beta$-catenin pathway
}

\author{
QIANQIAN JU ${ }^{1,2}$, MAORONG JIANG ${ }^{2,3}$, WENXIN HUANG ${ }^{4}$, \\ QINGBO YANG ${ }^{5}$, ZHENGHONG LUO $^{5}$ and HUI SHI ${ }^{1,5}$ \\ ${ }^{1}$ School of Basic Medical Sciences, Nanjing Medical University, Nanjing, Jiangsu 211166; \\ ${ }^{2}$ Key Laboratory for Neuroregeneration, Medical College of Nantong University, Nantong, Jiangsu 226001; \\ ${ }^{3}$ School of Life Sciences, Nantong University, Nantong, Jiangsu 226019; ${ }^{4}$ Department of General Surgery, \\ Shanghai General Hospital, Shanghai Jiao Tong University School of Medicine, Shanghai 200080; \\ ${ }^{5}$ Department of Thoracic Surgery, Shanghai Tenth People's Hospital, Shanghai 200072, P.R. China
}

Received July 8, 2021; Accepted October 13, 2021

DOI: $10.3892 /$ or.2021.8240

\begin{abstract}
C-terminal-binding protein 2 (CtBP2), a transcriptional co-repressor, plays a main role in tumorigenesis and in the development of multiple tumors. Transforming growth interacting factor (TGIF) is involved in a number of cellular signal transduction pathways and is related to tumor occurrence and development. In the present study, the proteins interacting with $\mathrm{CtBP} 2$ were identified and the mechanisms underlying the biological activity of CtBP2 in esophageal squamous cell carcinoma (ESCC) were investigated. The Search Tool for the Retrieval of Interacting Genes (STRING) database was used to search for known proteins interacting with CtBP2, and co-immunoprecipitation (Co-IP) assay was performed to validate the interactions. Reverse transcription-quantitative PCR (RT-qPCR), immunohistochemistry (IHC) and western blot analysis were performed to examine the expression levels of CtBP2 and TGIF in ESCC. The correlation between CtBP2 and TGIF was analyzed using Gene Expression Profiling Interactive Analysis (GEPIA) by Pearson's correlation analysis, and the co-localization of CtBP2 with TGIF in the ECA109 cells was identified using immunofluorescence staining. XAV939 treatment, CCK-8, 5-ethynyl-2'-deoxyuridine (EdU) staining, wound healing and Transwell assays were performed to investigate the signaling pathways involved in the biological activity of $\mathrm{CtBP} 2$ in ECA109 cells. According to the results obtained from STRING and Co-IP analysis, an interaction between CtBP 2 and TGIF was indicated, and
\end{abstract}

Correspondence to: Dr Hui Shi, School of Basic Medical Sciences, Nanjing Medical University, 101 Longmian Avenue, Jiangning, Nanjing, Jiangsu 211166, P.R. China

E-mail: disney1982@163.com

Key words: esophageal squamous cell carcinoma, CtBP2, TGIF, $\mathrm{Wnt} / \beta$-catenin, proliferation, migration, invasion these proteins were co-localized in the nucleus. CtBP2 and TGIF mRNA and protein expression levels were robustly and simultaneously increased in both ESCC tissues and cell lines. There was a direct correlation between $\mathrm{CtBP} 2$ and TGIF expression levels in ESCC tissues, and both were significantly associated with metastasis and survival. The TGIF and CtBP2 expression levels were significantly increased or decreased simultaneously, in ECA109 cells transfected with LV-CtBP2 or sh-CtBP2, and vice versa. According to the results of CCK-8 assay, EdU staining and Transwell assay, CtBP2 promoted the proliferation, migration and invasion of ECA109 cells through the Wnt/ $\beta$-catenin pathway. On the whole, the present study demonstrates that CtBP2 interacts with TGIF and promotes the malignant progression of ESCC through the Wnt/ $\beta$-catenin pathway.

\section{Introduction}

A high incidence of esophageal cancer (EC) has been reported in China $(1,2)$. Recent surveys have demonstrated that there are $\sim 450,000$ new cases of EC each year worldwide, with more than half of these cases originating from China, ranking sixth among the list malignant tumors in China $(3,4)$. EC is an invasive from of cancer, with the two main pathological types being esophageal squamous cell carcinoma (ESCC) and esophageal adenocarcinoma (EA) (5). ESCC has been reported as the main histological type of EC in China, accounting for $>95 \%$ of reported cases $(6,7)$. The 5 -year survival rate of patients with EC is only $\sim 10 \%$, and the recurrence and mortality rates remain high (8). Radiotherapy, chemotherapy and targeted therapy have been developed in recent years for the treatment of EC. However, the clinical efficacy and prognosis of patients have not been satisfactory $(9,10)$. This is due to the lack of an in-depth understanding of the pathogenesis of EC (11). Therefore, a more detailed elucidation of the pathogenesis of EC at the molecular level may lead to the discovery of an ideal molecular target or other effective therapeutic drugs for EC. 
The transcriptional co-repressor C-terminal binding protein $(\mathrm{CtBP})$ has been originally named thus, since it binds to the five amino acid domains (PLDLS) at the C-terminus of the adenovirus early region $1 \mathrm{~A}$ (E1A) protein (12-14). The CtBP protein, including the CtBP1 and CtBP2 protein isoforms, is an evolutionarily conserved transcriptional repressor that has been reported to specifically bind to DNA or protein targets and function as a bridge molecule between DNA-binding proteins and transcriptional repressors, thereby inhibiting gene transcription (15). In addition, CtBP has been revealed to promote epithelial-mesenchymal transition (EMT) by inhibiting E-cadherin expression $(14,16)$. Furthermore, it may function as a transcriptional co-repressor, negatively regulating certain tumor suppressors, thereby promoting the occurrence and development of tumors $(17,18)$. Recent studies have revealed that the $\mathrm{CtBP}$ family plays a crucial role in the occurrence and development of breast, colon, ovarian and prostate cancer (19-21).

A previous study by the authors found that the expression of CtBP2 was significantly increased in ESCC tissues, and was positively associated with the tumor histological grade, and negatively associated with p16 tumor suppressor gene expression (22). In addition, CtBP2 has been demonstrated to promote ECA109 cell proliferation and migration, and reduce cell susceptibility to cisplatin (23). Moreover, cyclin H/cyclin-dependent kinase 7 (CCNH/CDK7) has been previously reported to competitively bind to homeodomain-interacting protein kinase 2 (HIPK2) and CtBP2, thereby inhibiting the phosphorylation and dimerization of CtBP2, ultimately regulating its stability in breast cancer cells (24). CtBP2 has been also revealed to promote the proliferation and migration, as well as inhibit the apoptosis of ESCC cells, through the regulation of its downstream target molecule, basic fibroblast growth factor (FGF2) (25). These results suggest that $\mathrm{CtBP} 2$ is involved in the occurrence and development of ESCC; however, the underlying mechanisms remain unknown. Therefore, it was hypothesized that $\mathrm{CtBP} 2$, as a transcriptional co-repressor, may also interact with other proteins and participate in the development of ESCC.

The transforming growth-interacting factor (TGIF) gene is located on chromosome 18p11 and encodes a nuclear protein composed of 272 amino acid residues with a molecular weight of $\sim 30 \mathrm{kDa}$ (26). It belongs to the family of three amino acid loop extensions (TALEs), which are expressed in various cells and tissues $(27,28)$. TGIF has been reported to be involved in a number of cellular signal transduction pathways, particularly the TGF- $\beta$ pathway (29). It has been demonstrated that TGIF can bind to Smad2 and Smad3, possibly changing chromatin structure from loose to dense through the recruitment of histone deacetylase (HDAC), thereby inhibiting the transcription of target genes mediated by TGF- $\beta$ (29). TGIF can also inhibit the TGF- $\beta$ signaling pathway through a Smad-independent mechanism, by recruiting HDAC (30). Previous research has confirmed that TGIF expression is increased in various tumors and may be related to the occurrence and development of tumors $(26,31,32)$. In addition, it was revealed in a previously published study that high levels of TGIF were associated with high levels of Wnt signaling pathway components (Axin1, Axin2 and $\beta$-catenin) and a poor survival rate of patients with triple-negative breast cancer (33). Therefore, it was hypothesized that an in-depth study of the regulatory mechanisms between CtBP2 and TGIF may be of utmost significance, in order to clarify the roles of CtBP2 and TGIF in the occurrence and development of ESCC.

\section{Materials and methods}

Patients and tissue samples. A total of 108 patients with ESCC were identified and enrolled from 2015 to 2019 at the Affiliated Hospital of Nantong University (Nantong, China). None of the patients had previously received radiotherapy, chemotherapy, or immunotherapy prior to surgery. All fresh tissues (ESCC tissues and matched adjacent tissues) were collected following surgical resection, were immediately washed with sterile phosphate-buffered saline (PBS) and immediately fixed in $4 \%$ paraformaldehyde (PFA) for $12 \mathrm{~h}$ before being embedded in paraffin or stored at $-80^{\circ} \mathrm{C}$. Patient written informed consent was obtained before the commencement of the study, according to the guidelines of the Ethics Committee of the Affiliated Hospital of Nantong University, and ethics approval was also provided from the respective ethics committee (2015 L132).

Cells and cell culture. The human ESCC cell lines, ECA109 (CC-Y1150), TE-1 (TCHu 89) and KYSE-150 (TCHu236), and the human normal esophageal epithelial cell line, HEEC (CL0420), were provided by the Cell Bank of Type Culture Collection of the Chinese Academy of Sciences and were cultured in high-glucose DMEM (Gibco; Thermo Fisher Scientific, Inc.) supplemented with $10 \%$ FCS (Shanghai Shuangru Biotechnology Co., Ltd.) and 1\% penicillin/streptomycin antibiotic solution (Beijing Solarbio Science \& Technology Co., Ltd.). All cell lines were cultured at $37^{\circ} \mathrm{C}$ with $5 \% \mathrm{CO}_{2}$.

Lentiviral transduction. To knockdown or overexpress CtBP2 and TGIF, recombinant lentiviral vectors (sh-CtBP2, sh-TGIF, LV-CtBP2 and LV-TGIF, respectively) were constructed (Vigen Biotechnology) (23). The coding sequence of CtBP2 or TGIF was cloned as an overexpression vector, into a GV492 vector (Vigen Biotechnology). The shRNA of CtBP2 or TGIF, whose target sequence was 5'-GCGCCTTGGTCAGTAATAG-3' or 5'-AGCTTCTAGTGGATGTTGC-3', was cloned into a GV248 vector, respectively. The lentiviral particles were obtained from Vigen Biotechnology Co. Ltd. Briefly, 293T packaging cells (The Cell Bank of Type Culture Collection of the Chinese Academy of Sciences) were co-transfected with shutter plasmids and packaging vectors using polyethyleneimine (PEI; Shanghai life ilab Biotechnology; http://life-ilab. $\mathrm{com} /$ ) and incubated in $5 \% \mathrm{CO}_{2}, 37^{\circ} \mathrm{C}$ incubator for overnight. The following day, the $293 \mathrm{~T}$ cells were supplemented with fresh medium. The supernatant was collected at 48 and $72 \mathrm{~h}$ and post-transfection filtered through $0.45-\mu \mathrm{m}$ filter, and then concentrated with lentivirus concentration solution. Briefly, the supernatant from $293 \mathrm{~T}$ cells co-transfected with pMD2G, psPAX2 and shutter plasmids was collected and centrifuged at $2,000 \mathrm{x}$ g for $10 \mathrm{~min}$ and then filtered through $0.45-\mu \mathrm{m}$ filters to remove cells and debris. In total, four volumes of clarified supernatant were mixed with one volume of concentration reagent. The mixture was incubated at $4^{\circ} \mathrm{C}$ overnight followed by centrifugation at $1,500 \times \mathrm{g}$ for $45 \mathrm{~min}$ at $4^{\circ} \mathrm{C}$. Following 
centrifugation, the off-white pellet was re-suspended by PBS. The ECA109 cells were then transfected with recombinant lentiviral vectors and negative control viruses at a multiplicity of infection (MOI) of 5 . The following formula was used to calculate to volume of virus to be added: Virus volume $=$ MOI x cell number/virus titer. In addition, $1 \mu \mathrm{g} / \mathrm{ml}$ polybrene was added, to improve the transduction efficiency. The mixture was centrifuged at $800 \mathrm{x}$ g for $50 \mathrm{~min}$ at $32^{\circ} \mathrm{C}$. Following centrifugation, the cells were seeded into 6-well culture dish and incubated at $37^{\circ} \mathrm{C}$ overnight. Transfected ECA109 cells were selected using $2.5 \mu \mathrm{g} / \mathrm{ml}$ puromycin for 1 week. The efficiency of lentivirus-mediated knockdown or overexpression of CtBP2 or TGIF was verified using reverse transcription-quantitative PCR (RT-qPCR) and western blot analysis.

$R T-q P C R$. Total RNA extraction and reverse transcription were performed as previously described (23). Total RNA from cells or tumor tissues was extracted using TRIzol ${ }^{\circledR}$ LS reagent (Invitrogen; Thermo Fisher Scientific, Inc.) according to the manufacturer's instructions and was quantified using the NanoDrop ND-1000 spectrophotometer (Thermo Fisher Scientific, Inc.). cDNA was synthesized by reverse transcription using the PrimeScript RT reagent kit (Takara Bio, Inc.). qPCR was performed using SYBR Premix Ex Taq II (Tli RNaseH Plus; Takara Bio Inc.) on a LightCycler 96 system (Roche Diagnostics). Primers were synthesized by Sangon Biotech Co., Ltd. The thermocycling conditions were as follows: Firstly $95^{\circ} \mathrm{C}$ for $10 \mathrm{~min}$, followed by $95^{\circ} \mathrm{C}$ for $10 \mathrm{sec}, 60^{\circ} \mathrm{C}$ for $15 \mathrm{sec}$ and $72^{\circ} \mathrm{C}$ for $20 \mathrm{sec}$, for 40 cycles. Data were analyzed using the $2^{-\Delta \Delta \mathrm{Cq}}$ method with GAPDH as the internal reference control (34). All results are expressed as the mean \pm standard deviation of three independent experiments. The following primer sequences were used: GAPDH sense, 5'-GACCTGACCTGCCGTCTA-3' and antisense, 5'-AGGAGTGGGTGTCGCTGT-3'; CtBP2 sense, 5'-CTGAGTTCCTGGCCTTTCTG-3' and antisense, 5'-GACTTGATATCCGCGTCCTC-3'; TGIF sense, 5'-GGA TGAGGACAGCATGGACA-3' and antisense, 5'-AGGCAT TGTAACGGTGCT CA-3'.

Protein extraction and western blot analysis. Cells or tissues were lysed with ice-cold lysis buffer (Beyotime Institute of Biotechnology), as previously described (23). The protein concentration of each sample was determined by BCA assay (Thermo Scientific, Inc.) according to the manufacturer's instructions. Proteins were separated via 10\% SDS-PAGE (50 $\mu \mathrm{g}$ protein/lane), and then blotted onto PVDF membranes (Bio-Rad, Hercules, CA). The membranes were blocked with Tris-buffered saline and $0.1 \%$ Tween-20 (TBST) supplemented with $5 \%$ non-fat milk for $2 \mathrm{~h}$ at room temperature, and the PVDF membranes were incubated with primary antibodies including, rabbit anti-TGIF (ab52955; 1:1,000; Abcam), mouse anti-CtBP2 (sc-17759; 1:200; Santa Cruz Biotechnology, Inc.) and rabbit anti- $\beta$-catenin (ab68183; 1:1,000; Abcam) overnight at $4^{\circ} \mathrm{C}$. Rabbit anti- $\beta$-actin (ab8227; $1: 1,000 ;$ Abcam) was used as an internal control. The membranes were then incubated with HRP-conjugated goat anti-rabbit IgG (A8919; 1:1,000) or rabbit anti-mouse IgG (A9044; 1:1000) (Sigma-Aldrich; Merck KGaA) secondary antibodies at room temperature for $2 \mathrm{~h}$. Finally, western blot images were visualized by incuba- tion with enhanced chemiluminescence detection reagent (SuperSignal $^{\text {TM }}$ West Pico PLUS Chemiluminescent Substrate, 34577) (Thermo Fisher Scientific, Inc.) at room temperature for $5 \mathrm{~min}$, and the bands were quantified using ImageJ (v1.48) software (National Institutes of Health).

Immunohistochemistry (IHC). Immunohistochemical staining was performed as previously described (22). Briefly, 4\% PFA-fixed ESCC tissue or normal tissue sections were deparaffinized in xylene, rehydrated in a graded alcohol series, and finally washed three times with $0.1 \mathrm{M}$ PBS. The slides were submerged in Tris-EDTA buffer $\left(100^{\circ} \mathrm{C}, 20 \mathrm{~min}\right)$ for antigen retrieval and cooled naturally at room temperature. The IHC kit was purchased from Zhongshan Golden Bridge Biotechnology Co., Ltd. (cat. no. SP-9000). The sections were blocked with $10 \%$ goat serum (containing $0.1 \%$ triton- 100 , reagent 2 ) for $30 \mathrm{~min}$ at $37^{\circ} \mathrm{C}$ following treatment with reagent 1 (endogenous peroxidase blockers) for $5 \mathrm{~min}$, followed by incubation with CtBP2 (sc-17759; 1:200; Santa Cruz Biotechnology, Inc.) or TGIF (ab52955; 1:1,000; Abcam) antibody overnight at $4^{\circ} \mathrm{C}$. After washing three times with $0.1 \mathrm{M}$ PBS, the sections were incubated with reagent 3 [HRP-conjugated goat anti-rabbit IgG (A8919; 1:1,000) or HRP-conjugated rabbit anti-mouse IgG (A9044; 1:1000, Sigma-Aldrich; Merck KGaA) secondary antibodies] for $1 \mathrm{~h}$ at $37^{\circ} \mathrm{C}$, and subsequently incubated with reagent 4 at $37^{\circ} \mathrm{C}$ for $1 \mathrm{~h}$. Subsequently, hematoxylin (Beyotime Institute of Biotechnology) was used for re-staining at room temperature for $2 \mathrm{~h}$, and finally the sections were dehydrated in graded alcohol until they were transparent in xylene. The scoring criteria (semi-quantitative method) were comprehensive and determined by the staining intensity and proportion of positively stained cells. The staining intensity score was as follows: 0 points for no staining, 1 point for weak staining (light yellow), 2 points for moderate staining (yellowish-brown), and 3 points for strong staining (brown). The score for the proportion of positive cells was as follows: 0 for $\leq 5 \%, 1$ for $5-25 \%, 2$ for $25-50 \%, 3$ for $50-75 \%$, 4 for $>75 \%$. A final score was obtained by multiplying the two scores, $0-4$ indicated negative, 4-8 was weakly positive, and $>8$ was strongly positive. CtBP2 and TGIF expression in ESCC tissues and normal tissues of patients were detected according to the aforementioned method and score. Low expression was observed in the negative and weak positive groups, whereas high expression was observed in the strongly positive group. After staining, five fields were randomly selected in each section (magnification, $\mathrm{x} 40$ ) under a microscope (Axio Imager 2; Carl Zeiss AG). The digitized images of immunohistochemistry were quantitatively analyzed using Image-Pro Plus 6.0 software (IPP 6.0; Media Cybernetics, Inc.).

$H \& E$ staining. $\mathrm{H} \& \mathrm{E}$ staining was used to distinguish tissue morphology as per the manufacturer's instructions (Beyotime Institute of Biotechnology). ESCC tissue or normal tissue sections (4\% PFA-fixed) were deparaffinized in xylene, then rehydrated in a graded alcohol series. Nuclear staining was performed with hematoxylin at room temperature for $10 \mathrm{~min}$ following by flushing with running water to yield the color blue. The sections were then differentiated with $1 \%$ hydrochloric acid ethanol for $3 \mathrm{sec}$ and then washing with running water was continued. The cytoplasm was stained with eosin at room temperature for $30 \mathrm{sec}$, followed by $95 \%$ ethanol twice for 
$5 \mathrm{~min}, 100 \%$ ethanol twice for $5 \mathrm{~min}, 100 \%$ ethanol + xylene for 5 min (1:1), xylene for 5 min twice, and finally sealed with neutral gum. H\&E staining was observed under a microscope (Axio Imager 2; Carl Zeiss AG).

Immunofluorescence. Staining reagents included CtBP2 (sc-17759; 1:200; Santa Cruz Biotechnology, Inc.) and TGIF (ab52955; 1:1,000; Abcam) primary antibodies, anti-mouse (SAB3701092) or anti-rabbit (F4890) secondary antibodies (MilliporeSigma), and Hoechst 33342 (Beyotime Institute of Biotechnology). The cells were digested with trypsin and pipetted vigorously to make a single-cell suspension. The cells were placed on glass coverslips (24-well plates), incubated at $37^{\circ} \mathrm{C}$ and fixed with $4 \%$ PFA for $20 \mathrm{~min}$ at $15-25^{\circ} \mathrm{C}$. The glass coverslips were then washed three times with PBS for $10 \mathrm{~min}$ each and blocked with $10 \%$ bovine serum albumin (BSA) for $2 \mathrm{~h}$ at $15-25^{\circ} \mathrm{C}$. Subsequently, all cells were incubated with primary antibody $(1: 200)$ overnight at $4^{\circ} \mathrm{C}$. The following day, the cells were incubated with secondary antibody $(1: 2,000)$ for $2 \mathrm{~h}$ at $15-25^{\circ} \mathrm{C}$. Finally, the cells were stained with Hoechst 33258 (Beyotime Institute of Biotechnology) at room temperature for $10 \mathrm{~min}$, fixed with anti-fade solution and imaged under a fluorescence microscope (Zeiss AG).

Co-immunoprecipitation (Co-IP) assay. The ECA109 cells were transfected with lentiviruses expressing CtBP2 or TGIF. At 1 week post-transfection, the cells were subjected to co-immunoprecipitation assay using a commercial kit (Prod\#26149; Thermo Fisher Scientific, Inc.). Briefly, firstly, for antibody immobilization, ultrapure water, 20X Coupling Buffer and $10 \mu \mathrm{g}$ affinity-purified antibody were added directly to the agarose $(50 \%$ protein $\mathrm{A} / \mathrm{G}$ agarose with ratio of $100 \mu \mathrm{l}$ for a $1 \mathrm{ml}$ sample) in the spin column. Secondly, for the lysis of the cell cultures, the culture medium was carefully removed from the cells. The cells were then washed once with $1 \mathrm{X}$ modified Dulbecco's PBS. This was followed by the addition of $400 \mu \mathrm{l}$ per well ice-cold IP lysis/wash buffer $(2 X 50 \mathrm{ml}$, $0.025 \mathrm{M}$ Tris, $0.15 \mathrm{M} \mathrm{NaCl}, 0.001 \mathrm{M}$ EDTA, $1 \%$ NP-40, $5 \%$ glycerol; $\mathrm{pH}$ 7.4) to the cells cultured in a 6-well plate. The cells were then incubated on ice for $5 \mathrm{~min}$ with periodic mixing. The lysate was then transferred to a microcentrifuge tube and centrifuged at $\sim 13,000 \mathrm{x} \mathrm{g}$ at $4^{\circ} \mathrm{C}$ for $10 \mathrm{~min}$ to pellet the cell debris. The agarose and cell proteins were then mixed and appropriate experimental controls were prepared, followed by rocking overnight at $4^{\circ} \mathrm{C}$. The column was then centrifuged at $1,000 \times \mathrm{g}$ at $4^{\circ} \mathrm{C}$ for $1 \mathrm{~min}$. The protocol uses the IP Lysis/Wash Buffer $(1 \mathrm{M} \mathrm{NaCl})$ for coupling and washing the immune complex. The spin column was then placed in a new collection tube. This was followed by the addition of $50 \mu \mathrm{l}$ elution buffer and centrifugation. The tube was centrifuged at $1,000 \times \mathrm{g}$ at $4^{\circ} \mathrm{C}$ for $1 \mathrm{~min}$ and the flow-through was collected and analyze for protein. The resulting immuno-complex was analyzed using western blot analysis, with an anti-TGIF (ab52955; 1:1,000; Abcam) or anti-CtBP2 (sc-17759; 1:200; Santa Cruz Biotechnology, Inc.) antibody. To eliminate heavy chain signals, a light chain-specific secondary antibody (cat. no. 58802; Cell Signaling Technology, Inc.) was used.

$C C K-8$ assay. Cell viability was measured using CCK- 8 assay (Dojindo Molecular Technologies, Inc.) according to the manu- facturer's instructions in three independent experiments. The transfected ECA109 cells at a density of $5 \times 10^{3}$ cells/well were seeded in 96-well plates with $100 \mu 110 \%$ FBS. After culturing the cells for 24, 48 and $72 \mathrm{~h}$ with $(10$ and $100 \mathrm{nM}$, and 1, 10 and $100 \mu \mathrm{M}$ ) XAV939 (Wnt signaling pathway inhibitor; Merck $\mathrm{KGaA})$ at $37^{\circ} \mathrm{C}, 10 \mu \mathrm{l} \mathrm{CCK}-8$ reagent were added to each well and incubated at $37^{\circ} \mathrm{C}$ for a further $4 \mathrm{~h}$. Cell viability was then measured based on the absorbance at $450 \mathrm{~nm}$ wavelength (OD450) using a microplate reader (BioTek Instruments, Inc.).

5-Ethynyl-2'-deoxyuridine (EdU) staining. Cell proliferation of the transfected ECA109 cells upon XAV939 treatment was investigated using EdU staining assay. Briefly, $1 \times 10^{5}$ transfected ECA109 cells were resuspended in $200 \mu \mathrm{l}$ DMEM, and then seeded into 24-well plates. Following incubation for $48 \mathrm{~h}$ with $10 \mu \mathrm{M}$ XAV939, the cells were stained with EdU (Beyotime Institute of Biotechnology) at room temperature for 30 min against exposure to light. The cells were re-stained with Hoechst 33342 for $10 \mathrm{~min}$ in the dark, followed by washing with PBS. The number of EdU-positive cells was photographed, and five randomly selected fields were counted, using a fluorescence microscope (Carl Zeiss AG) (magnification, $\mathrm{x} 200)$. The experiments were performed in triplicate.

Wound healing assay. The migration of the transfected ECA109 cells upon XAV939 treatment was investigated using a wound healing assay, as previously described (35). To ensure the consistency of each initial scratch, a scratch chamber was used to carry out the experiment. Briefly, $5 \times 10^{4}$ transfected ECA109 cells were seeded into the scratch chamber (70 $\mu 1$ cell suspension for each side of the scratch chamber), and then cultured overnight to adhere, followed by the removal of the scratch chamber. The cells were then washed twice with PBS, in order to remove any non-adherent cells. Before scratching, the cells were cultured in high-glucose DMEM containing $10 \%$ FBS and supplemented with $1 \%$ penicillin/streptomycin mixture (36). To ensure the consistency of each initial scratch, ibidi Culture-Inserts (ibidi $\mathrm{GmbH}$ ) were used to carry out the experiment. Briefly, $5 \times 10^{4}$ transfected ECA109 cells were seeded into the ibidi Culture-Inserts ( $70 \mu \mathrm{l}$ cell suspension for each side of the scratch chamber), and then cultured overnight to adhere, followed by the removal of the ibidi Culture-Inserts. Following the removal of the ibidi Culture-Inserts, the scratch wound was created. After scratching was complete, the cells were cultured in high-glucose DMEM containing 2\% FBS and supplemented with $1 \%$ penicillin/streptomycin mixture. The migration (wound closure) of the indicated cells was monitored and photographed randomly at 0,24 and $48 \mathrm{~h}$. The wound healing rate $(\%)=(\mathrm{x} \mathrm{h}$ scratch area $-0 \mathrm{~h}$ scratch area $) / 0 \mathrm{~h}$ scratch area $\times 100$. Independent experiments were performed at least three times.

Transwell assay. The cell migratory and invasive abilities were examined using a Transwell assay, as previously described (35). Briefly, for the migration assay, $1 \times 10^{5}$ transfected ECA109 cells were resuspended in $200 \mu \mathrm{l}$ DMEM, and then seeded into the upper chamber of the Transwell ( $8 \mu \mathrm{m}$ pore size; Corning, Inc.) in 24-well plates. For the invasion assay, the upper chambers were coated with Matrigel matrix (50 $\mu \mathrm{l}$, BD Biosciences) before seeding the cells, and $500 \mu 1$ of $10 \%$ FBS were added 
A

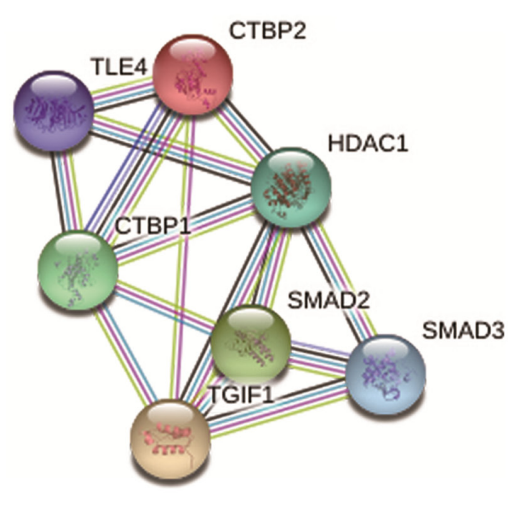

B

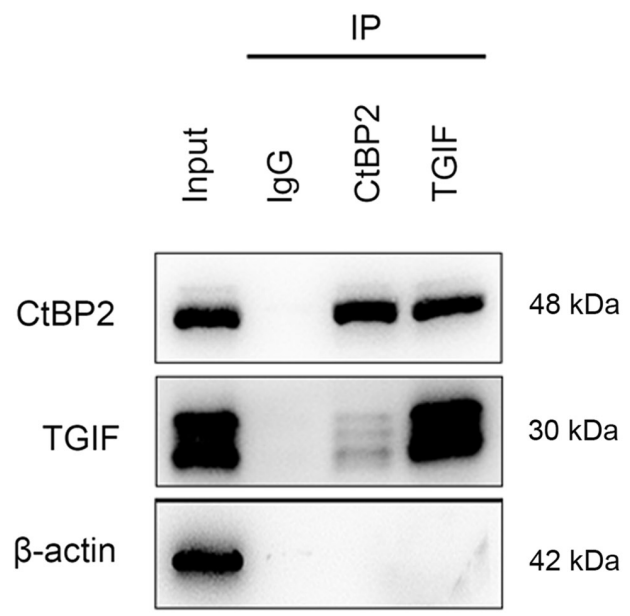

Figure 1. Interaction between CtBP2 and TGIF. (A) Visualization of CtBP2 protein network based on STRING database analysis. (B) Western blot analysis of immuno-complexes. The cells were lysed, and immunoprecipitation was performed with anti-TGIF or anti-CtBP2 antibody. The immuno-complexes were then subjected to western blot analysis. IgG was used as the negative control. IP, immunoprecipitation; CtBP2, C-terminal-binding protein 2; TGIF, transforming growth interacting factor; STRING, Search Tool for the Retrieval of Interacting Genes.

to the lower chamber. Following incubation at $37^{\circ} \mathrm{C}$ for $48 \mathrm{~h}$ with $10 \mu \mathrm{M}$ XAV939, the non-migrating cells were removed using a cotton swab. However, the migrated or invaded cells on the underside were fixed with $4 \%$ PFA and stained with $0.1 \%$ crystal violet (Beyotime Institute of Biotechnology) at room temperature for $\sim 40 \mathrm{~min}$. The number of migrating and invading cells was photographed, and cells in five randomly selected fields were counted using a phase contrast microscope (Leica DM IL LED) (magnification, x200). All experiments were performed in triplicate.

Bioinformatics analysis. The interactions between CtBP2 and predictive proteins were analyzed using the STRING database (https://string-db.org). Gene Expression Profiling Interactive Analysis (GEPIA) (http://gepia.cancer-pku.cn) was used to analyze the correlation between the expression of two interesting genes in a given tissue (37).

Statistical analysis. Statistical analysis was performed using GraphPad Prism version 8.0 (GraphPad Software, Inc.) or SPSS 23.0 (IBM Corp.). $\chi^{2}$ tests were performed to assess the clinical association between CtBP2 and TGIF expression and other tumor characteristics. Survival analysis was performed using the Kaplan-Meier method and the log-rank test. A Cox proportional hazards regression model was established to assess the factors independently associated with patient survival. Differences between two groups were compared using an unpaired or paired Student's t-test. To compare more than two groups, one-way ANOVA with post hoc Holm-Sidak correction for multiple comparisons was performed. All experimental data are presented as the mean $\pm \mathrm{SD}$. $\mathrm{P}<0.05$ was considered to indicate a statistically significant difference and all tests performed were two-sided.

\section{Results}

Interaction between CtBP2 and TGIF. The STRING database was used for the detection of known protein-protein interactions and predictive protein-protein interactions. The CtBP2 protein network is illustrated in Fig. 1A. As a predictive result, an interaction was detected between $\mathrm{CtBP} 2$ and TGIF.

Co-IP was performed to validate the interaction between CtBP2 and TGIF. Following ECA109 cell transfection with the with the CtBP2 or TGIF lentiviral transduction vector, the cells were subjected to Co-IP assay with anti-CtBP2 or anti-TGIF antibody. Immuno-complexes of CtBP2 and TGIF were observed using western blot analysis (Fig. 1B).

Expression levels of CtBP2 and TGIF in ESCC tissues and cells. RT-qPCR and western blot analysis were performed to examine the expression levels of CtBP2 and TGIF in ESCC tissues and cells. The mRNA expression levels of CtBP2 and TGIF were robustly increased simultaneously in the tumor tissues of representative patients with ESCC (Fig. 2A). Western blot analysis and IHC were performed to further confirm the CtBP2 and TGIF expression levels in ESCC tissues. Compared with the adjacent normal tissues, the expression levels of CtBP2 and TGIF were significantly upregulated simultaneously in ESCC tissues (Fig. 2B-E). RT-qPCR and western blot analysis were performed to evaluate the mRNA and protein expression levels of CtBP2 and TGIF in the ESCC cell lines. In comparison with the human normal esophageal epithelial cell line, HEEC, the mRNA and protein expression levels of both $\mathrm{CtBP} 2$ and TGIF were increased simultaneously in the ESCC cell lines. In ECA109 cells, the levels of CtBP2 and TGIF were the highest (Fig. 2F-H). These results revealed that CtBP2 and TGIF expression levels were significantly simultaneously increased in ESCC tissues and cells.

Association between CtBP2 and TGIF expression and clinicopathologic characteristics of patients with ESCC. The correlation between CtBP2 and TGIF expression levels in ESCC based on GEPIA by Pearson's correlation analysis is depicted in Fig. 3A. There was a direct correlation between the CtBP2 and TGIF expression levels in ESCC tissues, with a correlation coefficient of $\mathrm{R}=0.45(\mathrm{P}<0.05)$.

Subsequently, since there was a correlation between CtBP2 and TGIF expression levels in ESCC, their co-localization in 
A

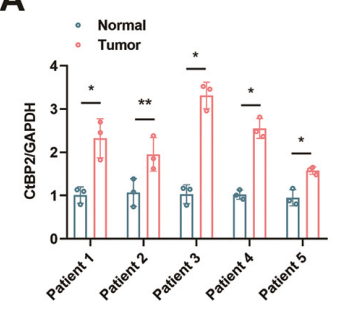

C

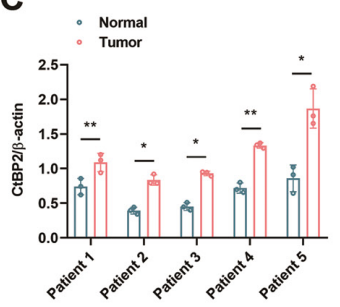

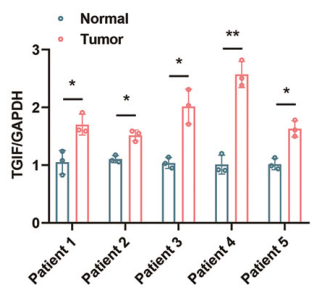

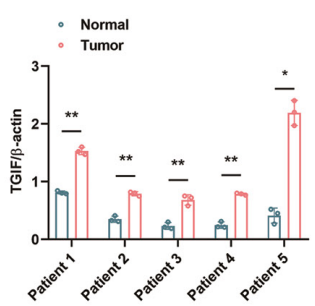

E

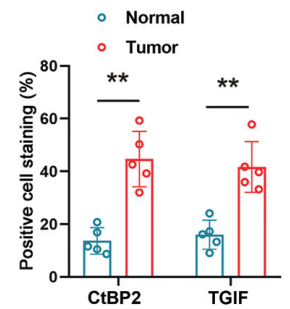

G

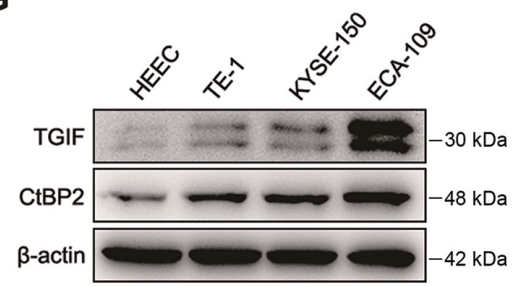

B

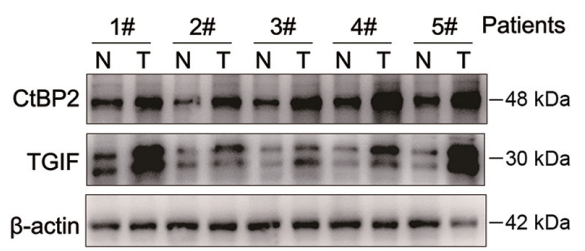

D

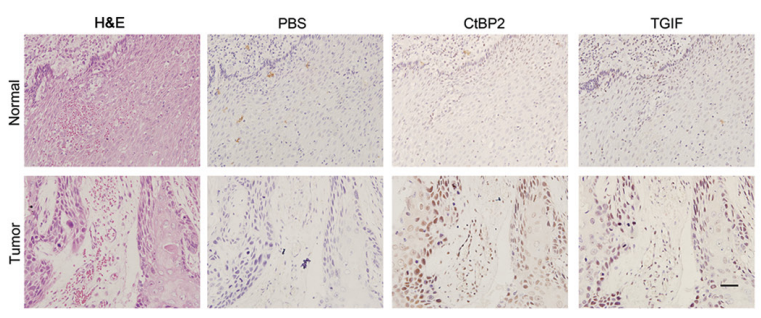

F

H
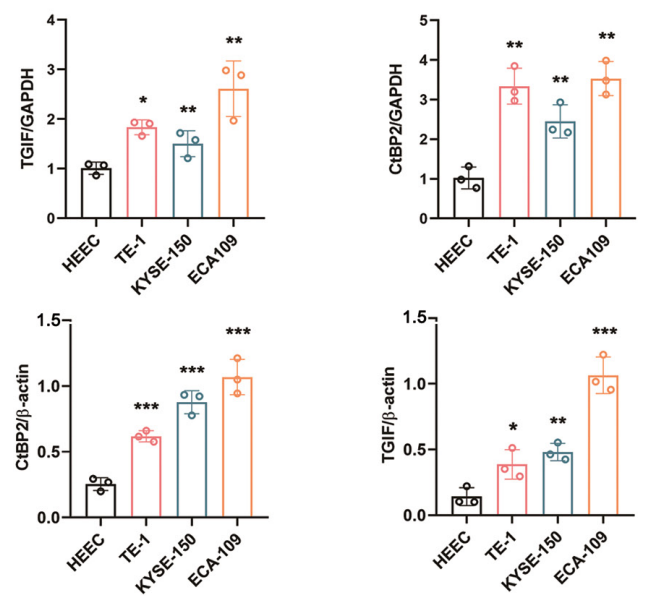

Figure 2. Expression levels of CtBP2 and TGIF in tissues or cells of ESCC. (A) mRNA expression levels of CtBP2 and TGIF in ESCC tissues were examined by RT-qPCR. (B) Expression levels of CtBP2 and TGIF in ESCC tissues were tested by western blot analysis. N, normal tissues; T, tumor tissues. (C) Statistical analysis of western blot analysis results. (D) Expression levels of CtBP2 and TGIF in ESCC tissues were tested by IHC. PBS was used as the negative control. Scale bar $=200 \mu \mathrm{m}$. (E) Statistical analysis of IHC results. (F) Expression levels of CtBP2 and TGIF in the human normal esophageal epithelial cell line, HEEC, and the human ESCC cell lines, ECA109, TE-1 and KYSE-150, were examined using western blot analysis. (G) mRNA expression levels of CtBP2 and TGIF in HEEC and ECA109, TE-1 and KYSE-150 cells were examined using RT-qPCR. (H) Statistical analysis of the western blots in panel F. Data are presented as the mean $\pm \mathrm{SD}$, and the Student's t-test and one-way ANOVA were performed. ${ }^{*} \mathrm{P}<0.05,{ }^{* * *} \mathrm{P}<0.01$ and ${ }^{* * *} \mathrm{P}<0.001$. CtBP2, C-terminal-binding protein 2 ; TGIF, transforming growth interacting factor; ESCC, esophageal squamous cell carcinoma; IHC, immunohistochemistry; RT-qPCR, reverse transcription quantitative -PCR.
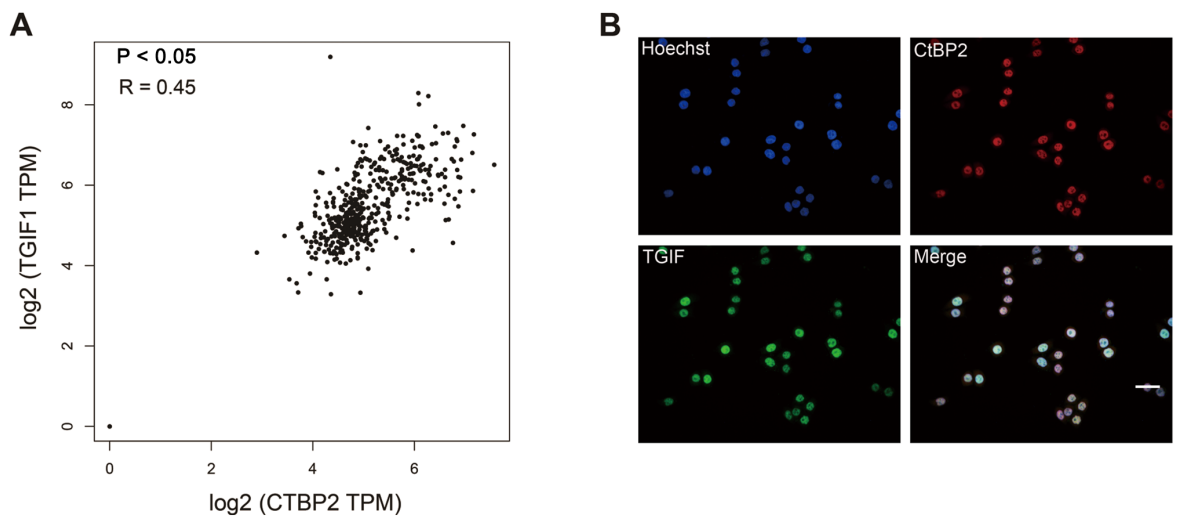

Figure 3. Correlation between CtBP2 and TGIF. (A) Scatter plot of the correlation between CtBP2 and TGIF expression levels in ESCC tissues based on GEPIA. There was a direct correlation between CtBP2 and TGIF expression in ESCC tissues with a correlation coefficient of $\mathrm{R}=0.45$ ( $\mathrm{P}<0.05$ ). (B) Co-localization of CtBP2 and TGIF expression in ECA109 cells was examined by using immunofluorescence. Scale bar, $50 \mu \mathrm{m}$. CtBP2, C-terminal-binding protein 2; TGIF, transforming growth interacting factor; ESCC, esophageal squamous cell carcinoma; GEPIA, Gene Expression Profiling Interactive Analysis. 
Table I. Association between CtBP2 and TGIF expression and the clinicopathological characteristics of patients with ESCC.

\begin{tabular}{|c|c|c|c|c|c|c|}
\hline \multirow[b]{2}{*}{ Characteristic } & \multicolumn{2}{|c|}{$\mathrm{CtBP} 2$} & \multirow[b]{2}{*}{ P-value } & \multicolumn{2}{|c|}{ TGIF } & \multirow[b]{2}{*}{ P-value } \\
\hline & Low & High & & Low & High & \\
\hline Age (years) & & & 0.912 & & & 0.742 \\
\hline$<60$ & 10 & 24 & & 14 & 20 & \\
\hline$\geq 60$ & 21 & 53 & & 28 & 46 & \\
\hline Sex & & & 0.154 & & & 0.55 \\
\hline Male & 21 & 62 & & 31 & 52 & \\
\hline Female & 10 & 15 & & 11 & 14 & \\
\hline Clinical stage & & & 0.147 & & & 0.175 \\
\hline I & 3 & 6 & & 6 & 3 & \\
\hline II & 24 & 47 & & 27 & 44 & \\
\hline III & 4 & 24 & & 9 & 19 & \\
\hline Histological differentiation & & & 0.053 & & & 0.379 \\
\hline Well & 5 & 15 & & 6 & 14 & \\
\hline Good & 12 & 45 & & 21 & 36 & \\
\hline Poor & 14 & 17 & & 15 & 16 & \\
\hline Tumor diameter $(\mathrm{cm})$ & & & 0.078 & & & 0.097 \\
\hline$<3$ & 12 & 17 & & 15 & 14 & \\
\hline$\geq 3$ & 19 & 60 & & 27 & 52 & \\
\hline T classification & & & 0.695 & & & 0.312 \\
\hline $\mathrm{T} 1$ & 3 & 11 & & 6 & 8 & \\
\hline $\mathrm{T} 2$ & 11 & 22 & & 16 & 17 & \\
\hline $\mathrm{T} 3$ & 17 & 44 & & 20 & 41 & \\
\hline $\mathrm{N}$ classification & & & 0.108 & & & 0.375 \\
\hline No & 20 & 47 & & 27 & 40 & \\
\hline N1 & 11 & 18 & & 13 & 16 & \\
\hline $\mathrm{N} 2$ & 0 & 11 & & 2 & 9 & \\
\hline N3 & 0 & 1 & & 0 & 1 & \\
\hline Metastasis & & & $0.015^{\mathrm{a}}$ & & & $0.014^{\mathrm{a}}$ \\
\hline No & 17 & 23 & & 22 & 18 & \\
\hline Yes & 14 & 54 & & 20 & 48 & \\
\hline Depth & & & 0.493 & & & 0.345 \\
\hline t0 & 1 & 1 & & 0 & 2 & \\
\hline $\mathrm{t} 1$ & 2 & 12 & & 6 & 8 & \\
\hline $\mathrm{t} 2$ & 11 & 19 & & 14 & 16 & \\
\hline $\mathrm{t} 3$ & 15 & 36 & & 16 & 35 & \\
\hline $\mathrm{t} 4$ & 2 & 9 & & 6 & 5 & \\
\hline Outcome & & & $0.003^{\mathrm{a}}$ & & & $0.001^{\mathrm{a}}$ \\
\hline Mortality & 18 & 21 & & 28 & 11 & \\
\hline Survival & 13 & 56 & & 14 & 55 & \\
\hline
\end{tabular}

Statistical analyses were performed using the $\chi^{2}$ test. ${ }^{\mathrm{P}}<0.05$ was considered to indicate a statistically significant difference. ESCC, esophageal squamous cell carcinoma; CtBP2, C-terminal-binding protein 2; TGIF, transforming growth interacting factor.

the ESCC cell line, ECA109, was examined. For this purpose, immunofluorescence staining was performed to evaluate CtBP2 and TGIF expression co-localization in ECA109 cells. The results demonstrated that $\mathrm{CtBP} 2$ and TGIF expression was co-localized in the nucleus of ECA109 cells (Fig. 3B).
A total of 108 patients with ESCC was enrolled, and the association between $\mathrm{CtBP} 2$ and TGIF expression and the patient clinicopathological characteristics was analyzed (Table I). The CtBP2 and TGIF expression levels were significantly associated with metastasis and survival $(\mathrm{P}<0.05)$. 
Table II. Univariate analyses of various prognostic parameters in patients with ESCC using Cox regression analysis.

\begin{tabular}{lccr}
\hline & \multicolumn{2}{c}{ Univariate analysis } \\
\cline { 2 - 4 } Parameter & Hazard ratio & $95 \%$ confidence interval & P-value \\
\hline Age & 1.473 & $0.867-2.503$ & 0.152 \\
Sex & 0.763 & $0.43-1.354$ & 0.355 \\
Clinical stage & 2.088 & $1.349-3.232$ & $0.001^{\text {a }}$ \\
Histological differentiation & 0.959 & $0.683-1.346$ & 0.807 \\
Tumor diameter & 2.381 & $1.299-4.364$ & $0.005^{\text {a }}$ \\
T classification & 1.497 & $1.049-2.137$ & $0.026^{\mathrm{a}}$ \\
N classification & 1.684 & $1.240-2.287$ & $0.001^{\mathrm{a}}$ \\
Metastasis & 1.240 & $0.747-2.058$ & 0.405 \\
Depth & 1.239 & $0.952-1.613$ & 0.112 \\
CtBP2 & 2.361 & $1.288-4.329$ & $0.005^{\mathrm{a}}$ \\
TGIF & 4.194 & $2.317-7.590$ & $0.001^{\mathrm{a}}$ \\
\hline
\end{tabular}

Statistical analyses were performed using the log-rank test. ${ }^{\mathrm{a}} \mathrm{P}<0.05$ was considered to indicate a statistically significant difference. ESCC, esophageal squamous cell carcinoma; CtBP2, C-terminal-binding protein 2; TGIF, transforming growth interacting factor.

A

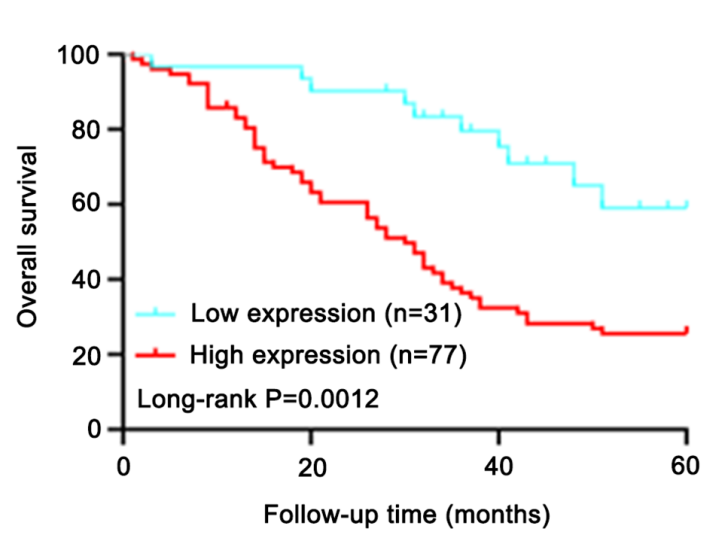

B TGIF

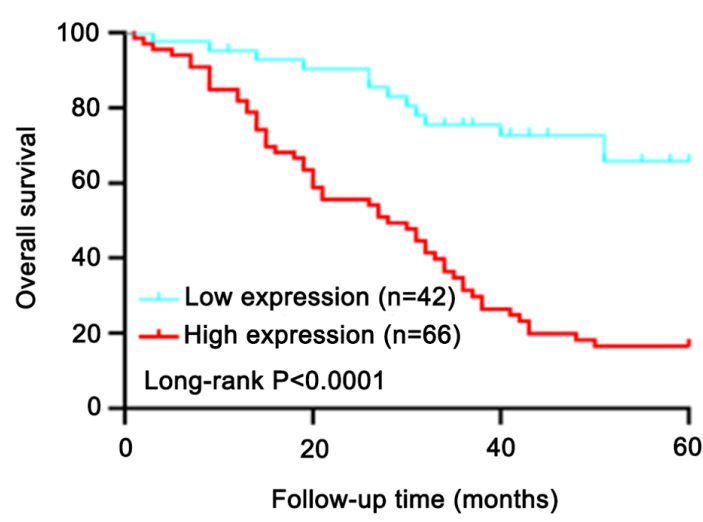

Figure 4. Survival curves of CtBP2 (A) or TGIF (B) expression in patients with ESCC. A total of 108 patients with follow-up data were evaluated and immunohistochemical staining followed by Kaplan-Meier survival analysis was performed. Patients with a low expression of CtBP2 or TGIF had a longer cumulative survival. CtBP2, C-terminal-binding protein 2; TGIF, transforming growth interacting factor; ESCC, esophageal squamous cell carcinoma.

Prognostic value of CtBP2 and TGIF expression. Kaplan-Meier analysis was performed to examine the association between CtBP2 or TGIF expression and the survival of patients with ESCC. A total of 108 patients with follow-up data were evaluated and IHC staining followed by Kaplan-Meier survival analysis was performed. The high vs. low expression of CtBP2 (Fig. 4A) or TGIF (Fig. 4B) differed significantly in the survival curves. Patients with a low expression of CtBP2 or TGIF had a longer cumulative survival. Univariate analysis, performed using the Cox proportional hazards regression model, revealed that $\mathrm{CtBP} 2(\mathrm{P}=0.005)$, TGIF $(\mathrm{P}=0.001)$, clinical stage $(\mathrm{P}=0.001)$, tumor diameter $(\mathrm{P}=0.005)$, $\mathrm{T}$ classification $(\mathrm{P}=0.026)$ and $\mathrm{N}$ classification $(\mathrm{P}=0.001)$ were independent prognostic indicators of overall survival (Table II).

Signaling pathway involved in the of biological activity of CtBP2 in ECA109 cells. To explore the biological activity of CtBP2 and TGIF in ECA109 cells, recombinant lentiviral vectors overexpressing CtBP2 and TGIF (LV-CtBP2 and LV-TGIF) or carrying shRNAs to knockdown (sh-CtBP2 and sh-TGIF) CtBP2 and TGIF expression were constructed. Since the recombinant lentiviral vectors contained the gene encoding the green fluorescent protein (GFP), the transfection rate could be evaluated directly under a fluorescence microscope. Following transfection, the fluorescence images demonstrated that the percentage of GFP-positive cells was $>90 \%$ (Fig. 5A, B, D and E). RT-qPCR was performed to further examine CtBP2 and TGIF mRNA expression in the ECA109 cells transfected with the vectors. In comparison with the negative control (NC), the CtBP2 and TGIF mRNA expression levels were significantly increased or decreased $(\mathrm{P}<0.05)$ following transfection in the ECA109 cells (Fig. 5C and F). In addition, western blot analysis was performed to examine the CtBP2 and TGIF expression levels in the ECA109 cells trans- 
A

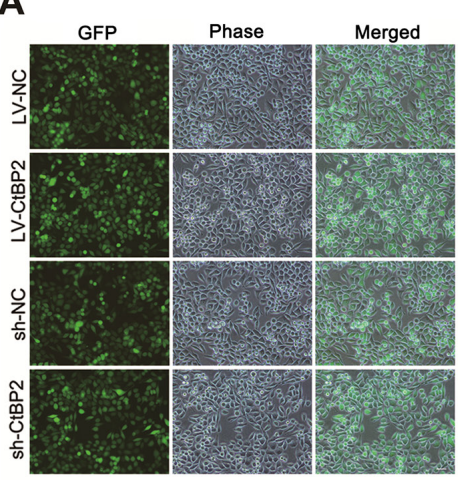

B

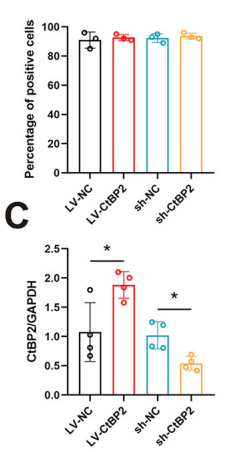

D

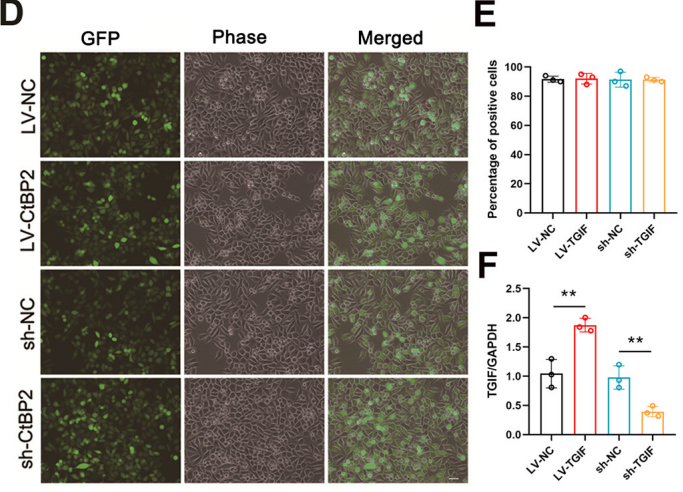

G

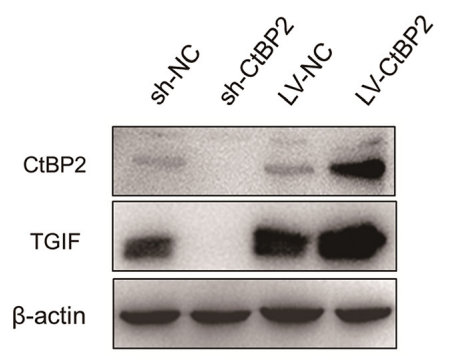

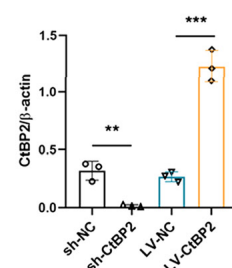

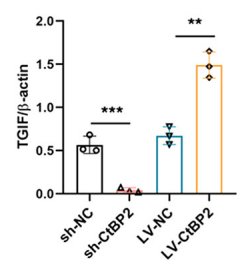

H

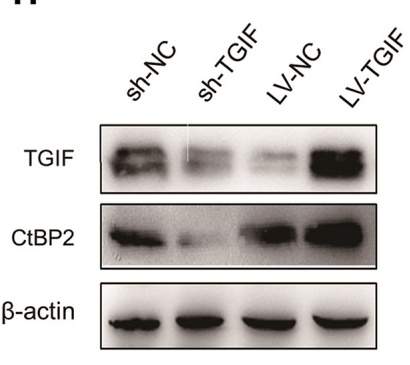

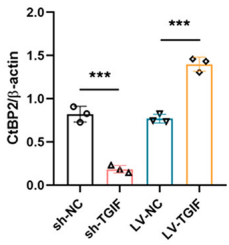

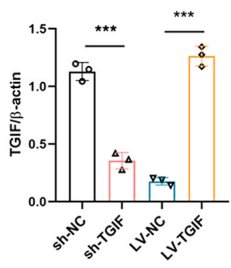

Figure 5. Overexpression or knockdown of CtBP2 and TGIF in ECA109 cells. (A and D) ECA109 cells were observed under a fluorescence and phase contrast microscope following transfection. The recombinant lentiviral vectors contained the gene encoding the green fluorescent protein. Scale bar, $500 \mu \mathrm{m}$. (B and E) statistical analysis of percentage of positive cells in panels A and D. (C and F) mRNA expression levels of CtBP2 and TGIF in ECA109 cells following transfection was examined using RT-qPCR. (G and H) Expression levels of CtBP2 and TGIF in ECA109 cells following transfection were examined using western blot analysis. Data are presented as the mean $\pm \mathrm{SD}$, and the Student's t-test and one-way ANOVA were performed. ${ }^{*} \mathrm{P}<0.05,{ }^{* * *} \mathrm{P}<0.01$ and ${ }^{* * * *} \mathrm{P}<0.001$. $\mathrm{NC}$, negative control; CtBP2, C-terminal-binding protein 2; TGIF, transforming growth interacting factor; RT-qPCR, reverse transcription quantitative PCR; $\mathrm{LV}$, overexpression of CtBP2 and TGIF; Sh, knockdown of CtBP2 and TGIF.

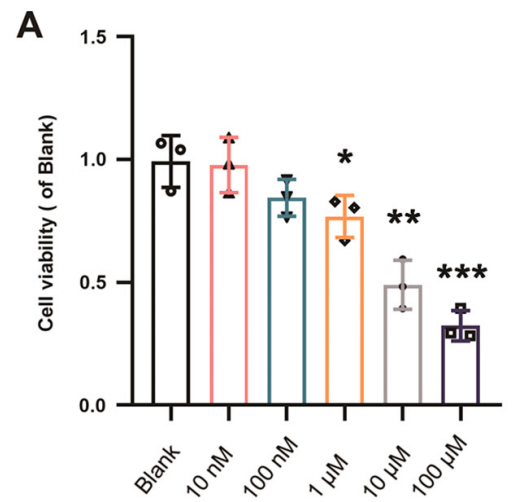

B
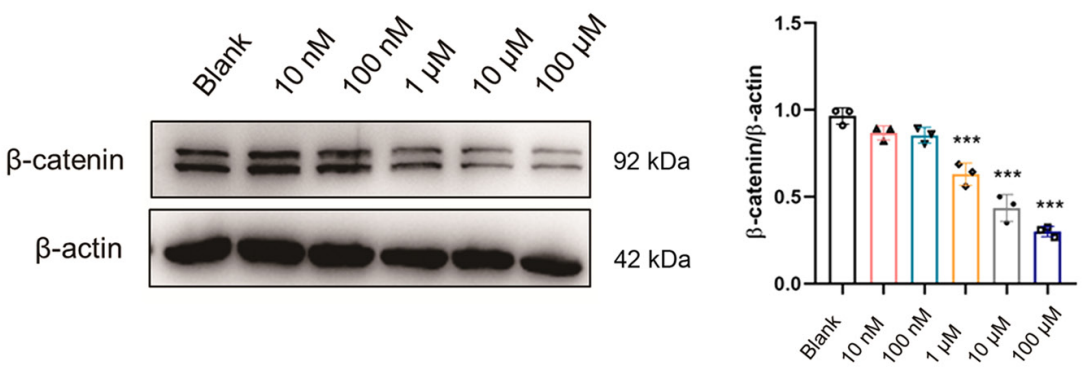

Figure 6. Effects of XAV939 on the viability and the expression of $\beta$-catenin in ECA109 cells. (A) Viability of ECA109 cells treated with various concentrations of XAV939 was examined using CCK-8 assay. (B) Expression of $\beta$-catenin in ECA109 cells treated with various concentrations of XAV939 was examined using western blot analysis. Data are presented as the mean $\pm \mathrm{SD}$, and the Student's t-test and one-way ANOVA were performed. ${ }^{*} \mathrm{P}<0.05,{ }^{* *} \mathrm{P}<0.01$ and ${ }^{* * *} \mathrm{P}<0.001$ vs. blank.

fected with the vectors. As was anticipated, the CtBP2 and TGIF expression levels increased or decreased following transfection in ECA109 cells, as compared with the NC. Of note, TGIF expression was robustly and simultaneously increased when CtBP2 expression was significantly upregulated in the cells transfected with LV-CtBP2 and simultaneously decreased when CtBP2 expression was significantly downregulated in the ECA109 cells transfected with sh-CtBP2 (Fig. 5G and H).

XAV939 is an inhibitor of the Wnt signaling pathway (38), and TGIF plays a role in tumorigenesis through Wnt signaling (33). Therefore, it was hypothesized that CtBP2 may interact with TGIF to promote the proliferation and migration 
A

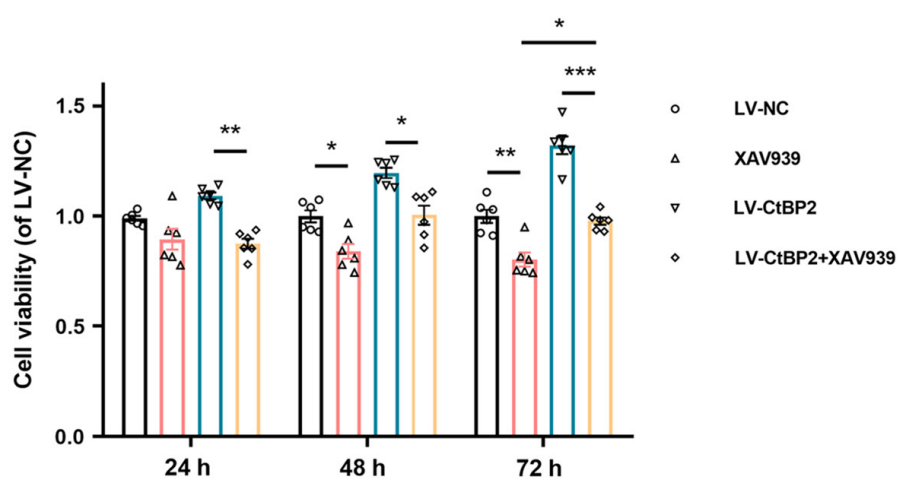

B

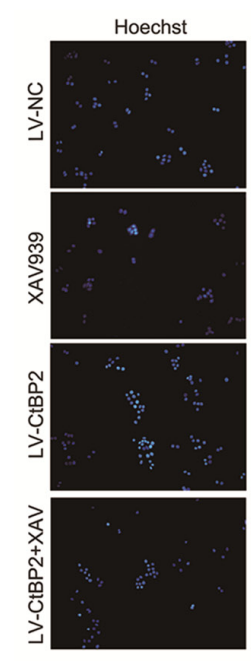

C

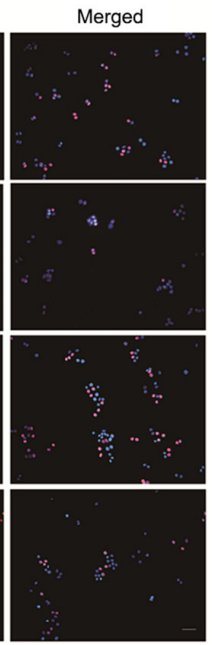

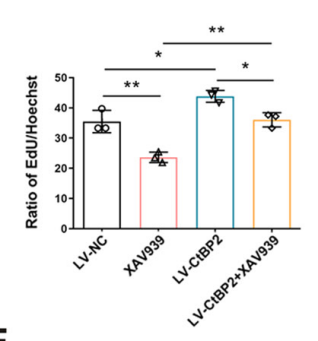

E

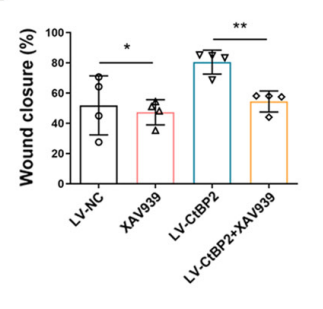

D
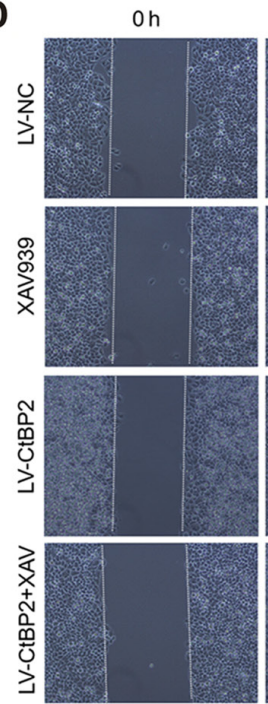

$48 \mathrm{~h}$
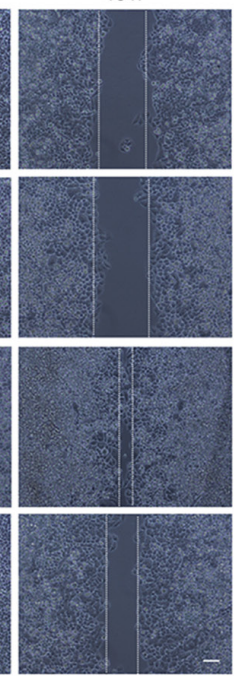

$\mathbf{F}$

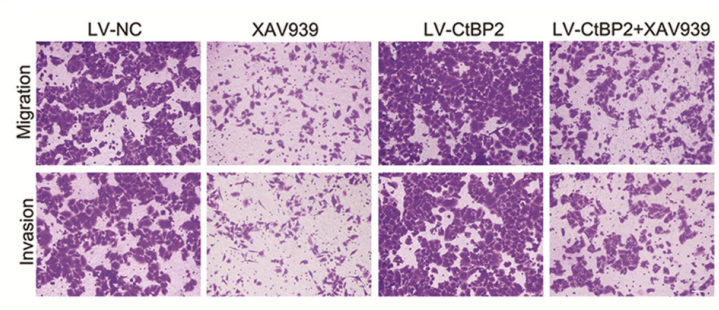

G
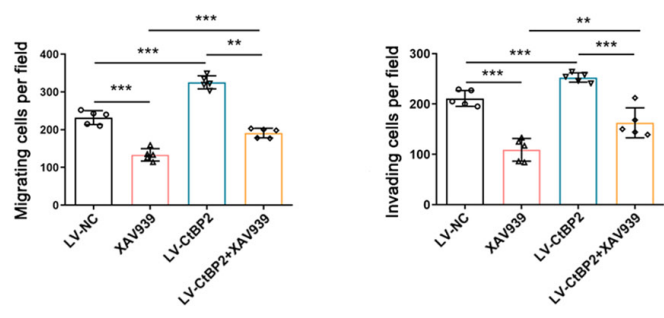

Figure 7. Signaling pathway involved in the biological activity of CtBP2 in ECA109 cells. (A) Viability of ECA109 cells transfected with LV-CtBP2 and treated with $10 \mu \mathrm{M}$ XAV939 for 24, 48 and $72 \mathrm{~h}$, was measured using CCK-8 assay. (B) The proliferation of ECA109 cells transfected with LV-CtBP2 and treated with $10 \mu \mathrm{M}$ XAV939 for $48 \mathrm{~h}$ was measured using EdU staining. Scale bar, $50 \mu \mathrm{m}$. (C) Statistical analysis of EdU staining results. (D) The migration of ECA109 cells transfected with LV-CtBP2 and treated with $10 \mu \mathrm{M}$ XAV939 for $48 \mathrm{~h}$ was measured using wound healing assay. Scale bar, $100 \mu \mathrm{m}$. (E) Statistical analysis of the wound healing assay results. (F) The migration and invasion of ECA109 cells transfected with LV-CtBP2 and treated with $10 \mu \mathrm{M} \mathrm{XAV939}$ for $48 \mathrm{~h}$ was measured using Transwell assay. Scale bar, $100 \mu \mathrm{m}$. (G) Statistical analysis of the Transwell assay results. Data are presented as the mean \pm SD, and the Student's t-test and one-way ANOVA were performed. ${ }^{*} \mathrm{P}<0.05,{ }^{* *} \mathrm{P}<0.01$ and ${ }^{* * *} \mathrm{P}<0.001$. CtBP2, C-terminal-binding protein 2 ; LV, lentiviral; EdU, 5-ethynyl-2'-deoxyuridine.

of ECA 109 cells through the Wnt/ $\beta$-catenin signaling pathway. First, the effects of XAV939 on cell viability and $\beta$-catenin expression were examined in the ECA109 cells. The results of CCK-8 assay revealed that cell viability was significantly decreased $(\mathrm{P}<0.05)$ in the ECA109 cells treated with XAV939 (10 and $100 \mathrm{nM}$, and 1, 10 and $100 \mu \mathrm{M}$ ) for $48 \mathrm{~h}$ (Fig. 6A). The expression of $\beta$-catenin was also significantly downregulated $(\mathrm{P}<0.001)$ in the ECA109 cells treated with XAV939 $(10 \mathrm{nM}$, $100 \mathrm{nM}, 1,10$ and $100 \mu \mathrm{M}$ ) for $48 \mathrm{~h}$ (Fig. 6B). Therefore, the optimal concentration of XAV939 that was used in subsequent experiments was $10 \mu \mathrm{M}$.
Furthermore, CCK- 8 assay was performed in order to measure the viability of the ECA109 cells transfected with LV-CtBP2 and treated with $10 \mu \mathrm{M}$ XAV939 for 24,48 and $72 \mathrm{~h}$. In comparison with the negative control (LV-NC), cell viability was markedly increased in the LV-CtBP2-transfected group; however, it was markedly decreased $(\mathrm{P}<0.05)$ in the XAV939 group, compared with the LV-NC-transfected group (Fig. 7A). These results indicated that XAV939 inhibited the CtBP2-mediated viability of ECA109 cells.

EdU staining was then employed to examine the effects of CtBP2 and XAV939 in ECA109 cells. The results 
demonstrated that the number of EdU-positive cells was significantly decreased $(\mathrm{P}<0.05)$ in the LV-CtBP2 + XAV939 group, compared with the LV-CtBP2-transfected group (Fig. 7B and C). This demonstrated that XAV939 inhibited the CtBP2-mediated proliferation of ECA109 cells. The results of wound healing and Transwell assays also revealed that XAV939 inhibited the CtBP2-mediated migration and invasion of ECA109 cells (Fig. 7D-G). These results indicate that CtBP2 exerts its biological activity through the Wnt/ $\beta$-catenin pathway in ECA109 cells.

\section{Discussion}

The extremely high incidence of EC in certain regions of China has prompted a number of researchers to investigate the disease pathogenesis and develop effective treatment strategies for this disease in China. Due to comprehensive tumorigenesis and the development of EC involving complex regulation of oncogenes and tumor suppressor genes, the in-depth elucidation of the pathogenesis of EC at the molecular level in order to identify an ideal molecular target or effective therapeutic drugs for EC is a promising therapeutic approach $(10,39)$. In the present study, the proteins interacting with CtBP2 were identified and the mechanisms of the biological activity of $\mathrm{CtBP} 2$ in ESCC were investigated.

CtBP2, a transcriptional co-repressor, acts as a bridge molecule between DNA-binding proteins and transcriptional repressors, in order to inhibit gene transcription by specifically binding to DNA-binding proteins and transcriptional repressors (12). Therefore, proteins interacting with $\mathrm{CtBP} 2$ were first determined in order to investigate the underlying mechanisms of CtBP2 biological activity in ESCC. The STRING database has been used for the detection of known protein-protein interactions and the prediction of protein-protein interactions (40). The results obtained from the STRING database indicated that there was an interaction between $\mathrm{CtBP} 2$ and TGIF and the subsequently performed Co-IP analysis indicated that these two proteins co-localized in the nucleus.

TGIF, a transcriptional repressor, is involved in a number of cellular signal transduction pathways, particularly the TGF- $\beta$ pathway (41). As an interaction between CtBP2 and TGIF was observed, the expression of TGIF and the correlation between CtBP2 and TGIF in ESCC was then examined. A previous study by the authors revealed that the expression of CtBP2 was significantly increased in ESCC tissues and was positively associated with the histological grade of the tumor (22). As was anticipated, the expression levels of CtBP2 and TGIF were significantly simultaneously increased in ESCC tissues and cells. GEPIA was used to further analyze the correlation between the expression of CtBP2 and TGIF in ESCC. There was a direct correlation between $\mathrm{CtBP} 2$ and TGIF expression in ESCC tissues, with a correlation coefficient of $\mathrm{R}=0.45$. These results indicated that the interaction of $\mathrm{CtBP} 2$ with TGIF plays a crucial role in ESCC.

The 5-year survival rate of patients with EC has been reported to be $\sim 10 \%$, and the recurrence and mortality rates remain high (8). Therefore, there is an urgent need for the identification of novel prognostic biomarkers for ESCC. In the present stuyd, Kaplan-Meier analysis was performed to examine the association between CtBP2 or TGIF expression and the survival of patients with ESCC. The results indicated that both CtBP2 and TGIF expression levels were significantly associated with metastasis and survival. Patients with a low expression of $\mathrm{CtBP} 2$ or TGIF had a longer cumulative survival. Therefore, CtBP2 and TGIF expression may serve as prognostic indicators of the clinical outcome of patients with ESCC.

XAV939 is an inhibitor of the Wnt signaling pathway (38), and high levels of TGIF are associated with high levels of the Wnt signaling pathway and a poor survival rate (33). Wnt exerts its effects through three signaling pathways, the most classic being the $\mathrm{Wnt} / \beta$-catenin signaling pathway, mediated by $\beta$-catenin (42). It has been reported that the abnormal activation of the Wnt/ $\beta$-catenin signaling pathway is involved in a number of diseases, including cancer, genetic diseases and organ fibrosis, as well as in the occurrence of EMT (43). Therefore, it was hypothesized that $\mathrm{CtBP} 2$, as a transcriptional co-repressor, may interact with TGIF and participate in the development of ESCC through the Wnt/ $\beta$-catenin signaling pathway. TGIF expression was robustly increased or decreased simultaneously when CtBP2 expression was significantly upregulated or downregulated, and vice versa. The results of CCK-8, EdU staining and Transwell assays indicated that CtBP2 promoted the proliferation, migration and invasion of ECA109 cells through the Wnt/ $\beta$-catenin pathway. In future studies, the authors aim to perform TCF reporter assay, in order to further verify the signaling pathway involved.

In conclusion, the present study demonstrates the existence of an interaction between CtBP2 and TGIF expression in ESCC, and these two proteins were co-localized in the nucleus. The CtBP2 and TGIF expression levels were robustly increased simultaneously in ESCC tissues and cell lines, and their expression was significantly associated with metastasis and survival. CtBP2 interacted with TGIF and promoted the progression of ESCC through the $\mathrm{Wnt} / \beta$-catenin pathway.

\section{Acknowledgements}

Not applicable.

\section{Funding}

The present study was supported by the China Postdoctoral Science Foundation (2018M632337), Natural Science Foundation of Shanghai (21ZR1449800), and the Natural Science Research Project of Nantong Science and Technology Bureau (XG202006-4).

\section{Availability of data and materials}

The datasets used and/or analyzed during the current study are available from the corresponding author on reasonable request.

\section{Authors' contributions}

QJ, MJ and HS contributed to the conception and design of the study. QJ and HS provided administrative support. QJ, MJ, WH, QY, ZL and HS provided all the study materials or patient clinicopathological data and samples. QJ, MJ, WH, QY and HS performed data collection and assembly. QJ, MJ, WH 
and HS contributed to data analysis and interpretation. QJ and HS confirmed the authenticity of all the raw data. QJ, MJ and HS wrote the manuscript. All authors have read and approved the final manuscript.

\section{Ethics approval and consent to participate}

Patient written informed consent was obtained before the study, according to the guidelines of the Ethics Committee of the Affiliated Hospital of Nantong University, and ethics approval has been also provided from the respective ethics committee (2015 L132).

\section{Patient consent for publication}

Not applicable.

\section{Competing interests}

The authors declare that they have no competing interests.

\section{References}

1. Lin Y, Totsuka Y, Shan B, Wang C, Wei W, Qiao Y, Kikuchi S, Inoue $\mathrm{M}$, Tanaka $\mathrm{H}$ and $\mathrm{He} \mathrm{Y}$ : Esophageal cancer in high-risk areas of China: Research progress and challenges. Ann Epidemiol 27: 215-221, 2017.

2. Yu C, Tang H, Guo Y, Bian Z, Yang L, Chen Y, Tang A, Zhou X, Yang X, Chen J, et al; China Kadoorie Biobank Collaborative Group: Hot tea consumption and its interactions with alcohol and tobacco use on the risk for esophageal cancer: a population-based cohort study. Ann Intern Med 168: 489-497, 2018.

3. Lin Y, Totsuka Y, He Y, Kikuchi S, Qiao Y, Ueda J, Wei W, Inoue $\mathrm{M}$ and Tanaka $\mathrm{H}$ : Epidemiology of esophageal cancer in Japan and China. J Epidemiol 23: 233-242, 2013.

4. Yang S, Lin S, Li N, Deng Y, Wang M, Xiang D, Xiang G, Wang S, Ye X, Zheng Y, et al: Burden, trends, and risk factors of esophageal cancer in China from 1990 to 2017: An up-to-date overview and comparison with those in Japan and South Korea. J Hematol Oncol 13: 146, 2020.

5. Anandavadivelan P and Lagergren P: Cachexia in patients with oesophageal cancer. Nat Rev Clin Oncol 13: 185-198, 2016.

6. Gao QY and Fang JY: Early esophageal cancer screening in China. Best Pract Res Clin Gastroenterol 29: 885-893, 2015.

7. Chen W, Li H, Zheng R, Ren J, Shi J, Cao M, Sun D, Sun X, Cao X, Zhou J, et al: An initial screening strategy based on epidemiologic information in esophageal cancer screening: A prospective evaluation in a community-based cancer screening cohort in rural China. Gastrointest Endosc 93: 110-118.e2, 2021.

8. Chen W, Li H, Ren J, Zheng R, Shi J, Li J, Cao M, Sun D, He S, Sun $\mathrm{X}$, et al: Selection of high-risk individuals for esophageal cancer screening: A prediction model of esophageal squamous cell carcinoma based on a multicenter screening cohort in rural China. Int J Cancer 148: 329-339, 2021.

9. Liu M, He Z, Guo C, Xu R, Li F, Ning T, Pan Y, Li Y, Ding H, Zheng L, et al: Effectiveness of intensive endoscopic screening for esophageal cancer in China: a community-based study. Am J Epidemiol 188: 776-784, 2019.

10. Kelly RJ: Emerging multimodality approaches to treat localized esophageal cancer. J Natl Compr Canc Netw 17: 1009-1014, 2019.

11. Borggreve AS, Kingma BF, Domrachev SA, Koshkin MA, Ruurda JP, van Hillegersberg R, Takeda FR and Goense L: Surgical treatment of esophageal cancer in the era of multimodality management. Ann N Y Acad Sci 1434: 192-209, 2018.

12. Chen L, Wang L, Qin J and Wei DS: CtBP2 interacts with ZBTB18 to promote malignancy of glioblastoma. Life Sci 262: $118477,2020$.

13. Wang H, Xiao Z, Zheng J, Wu J, Hu XL, Yang X and Shen Q: ZEB1 represses neural differentiation and cooperates with CTBP2 to dynamically regulate cell migration during neocortex development. Cell Rep 27: 2335-2353.e6, 2019.
14. Zhao LJ, Subramanian T, Vijayalingam S and Chinnadurai G: PLDLS-dependent interaction of E1A with CtBP: Regulation of CtBP nuclear localization and transcriptional functions. Oncogene 26: 7544-7551, 2007.

15. Jecrois AM, Dcona MM,Deng X, Bandyopadhyay D, Grossman SR, Schiffer CA and Royer WE Jr: Cryo-EM structure of CtBP2 confirms tetrameric architecture. Structure 29: 310-319.e5, 2021.

16. Ma Y, Sekiya M, Kainoh K, Matsuda T, Iwasaki H, Osaki Y, SuganoY,Suzuki H,Takeuchi Y,MiyamotoT,etal:Transcriptional co-repressor CtBP2 orchestrates epithelial-mesenchymal transition through a novel transcriptional holocomplex with OCT1. Biochem Biophys Res Commun 523: 354-360, 2020.

17. Wang DP, Gu LL, Xue Q, Chen H and Mao GX: CtBP2 promotes proliferation and reduces drug sensitivity in non-small cell lung cancer via the Wnt/ $\beta$-catenin pathway. Neoplasma 65: 888-897, 2018.

18. Thio SS, Bonventre JV and Hsu SI: The CtBP2 co-repressor is regulated by NADH-dependent dimerization and possesses a novel N-terminal repression domain. Nucleic Acids Res 32: 1836-1847, 2004.

19. Zhao Z, Hao D, Wang L, Li J, Meng Y, Li P, Wang Y, Zhang C, Zhou H, Gardner K, et al: CtBP promotes metastasis of breast cancer through repressing cholesterol and activating TGF- $\beta$ signaling. Oncogene 38: 2076-2091, 2019.

20. Dcona MM, Damle PK, Zarate-Perez F, Morris BL, Nawaz Z, Dennis MJ, Deng X, Korwar S, Singh SJ, Ellis KC, et al: Active-site tryptophan, the target of antineoplastic C-terminal binding protein inhibitors, mediates inhibitor disruption of $\mathrm{CtBP}$ oligomerization and transcription coregulatory activities. Mol Pharmacol 96: 99-108, 2019.

21. Thomas G, Jacobs KB, Yeager M, Kraft P, Wacholder S, Orr N, Yu K, Chatterjee N, Welch R, Hutchinson A, et al: Multiple loci identified in a genome-wide association study of prostate cancer. Nat Genet 40: 310-315, 2008.

22. Guan C, Shi H, Wang H, Zhang J, Ni W, Chen B, Hou S, Yang X, Shen A and Ni R: CtBP2 contributes to malignant development of human esophageal squamous cell carcinoma by regulation of p16INK4A. J Cell Biochem 114: 1343-1354, 2013.

23. Shi H, Mao Y, Ju Q, Wu Y, Bai W, Wang P, Zhang Y and Jiang M: $\mathrm{C}$-terminal binding protein-2 mediates cisplatin chemoresistance in esophageal cancer cells via the inhibition of apoptosis. Int $\mathrm{J}$ Oncol 53: 167-176, 2018.

24. Wang Y, Liu F, Mao F, Hang Q, Huang X, He S, Wang Y, Cheng C, Wang $\mathrm{H}, \mathrm{Xu} \mathrm{G}$, et al: Interaction with cyclin $\mathrm{H} /$ cyclin-dependent kinase 7 (CCNH/CDK7) stabilizes C-terminal binding protein 2 (CtBP2) and promotes cancer cell migration. J Biol Chem 288: 9028-9034, 2013.

25. Shi H, Xu J, Zhao R, Wu H, Gu L and Chen Y: FGF2 regulates proliferation, migration, and invasion of ECA109 cells through PI3K/Akt signalling pathway in vitro. Cell Biol Int 40: 524-533, 2016.

26. Shah A, Melhuish TA, Fox TE, Frierson HF Jr and Wotton D: TGIF transcription factors repress acetyl CoA metabolic gene expression and promote intestinal tumor growth. Genes Dev 33: 388-402, 2019.

27. Wang Y, Shi L, Li J, Li L, Wang H and Yang H: Long-term cadmium exposure promoted breast cancer cell migration and invasion by up-regulating TGIF. Ecotoxicol Environ Saf 175: 110-117, 2019.

28. Wotton D and Taniguchi K: Functions of TGIF homeodomain proteins and their roles in normal brain development and holoprosencephaly. Am J Med Genet C Semin Med Genet 178: 128-139, 2018.

29. NakashimaH, TsujimuraK,Irie K,Ishizu M,Pan M,Kameda Tand Nakashima K: Canonical TGF- $\beta$ signaling negatively regulates neuronal morphogenesis through TGIF/Smad complex-mediated CRMP2 suppression. J Neurosci 38: 4791-4810, 2018.

30. Sharma A, Sinha NR, Siddiqui S and Mohan RR: Role of 5'TG3'-interacting factors (TGIFs) in Vorinostat (HDAC inhibitor)-mediated Corneal Fibrosis Inhibition. Mol Vis 21: 974-984, 2015.

31. Du R, Shen W, Liu Y, Gao W, Zhou W, Li J, Zhao S, Chen C, Chen Y, Liu Y, et al: TGIF2 promotes the progression of lung adenocarcinoma by bridging EGFR/RAS/ERK signaling to cancer cell stemness. Signal Transduct Target Ther 4: 60, 2019.

32. Liu ZM, Tseng HY, Tsai HW, Su FC and Huang HS: Transforming grow th factor $\beta$-interacting factor-induced malignant progression of hepatocellular carcinoma cells depends on superoxide production from Nox4. Free Radic Biol Med 84: 54-64, 2015. 
33. Zhang MZ, Ferrigno O, Wang Z, Ohnishi M, Prunier C, Levy L Razzaque M, Horne WC, Romero D, Tzivion G, et al: TGIF governs a feed-forward network that empowers Wnt signaling to drive mammary tumorigenesis. Cancer Cell 27: 547-560, 2015.

34. Livak KJ and Schmittgen TD: Analysis of relative gene expression data using real-time quantitative PCR and the 2(-Delta Delta C(T)) method. Methods 25: 402-408, 2001.

35. Shi H, Shi J, Zhang Y, Guan C, Zhu J, Wang F, Xu M, Ju Q, Fang $S$ and Jiang M: Long non-coding RNA DANCR promotes cell proliferation, migration, invasion and resistance to apoptosis in esophageal cancer. J Thorac Dis 10: 2573-2582, 2018.

36. Mo Y, Wang Y, Zhang S, Xiong F, Yan Q, Jiang X, Deng X, Wang Y, Fan C, Tang L, et al: Circular RNA circRNF13 inhibits proliferation and metastasis of nasopharyngeal carcinoma via SUMO2. Mol Cancer 20: 112, 2021.

37. Tang Z, Li C, Kang B, Gao G, Li C and Zhang Z: GEPIA: A web server for cancer and normal gene expression profiling and interactive analyses. Nucleic Acids Res 45 (W1): W98-W102, 2017.

38. Shetti D, Zhang B, Fan C, Mo C, Lee BH and Wei K: Low dose of paclitaxel combined with XAV939 attenuates metastasis, angiogenesis and growth in breast cancer by suppressing Wnt signaling. Cells 8: 8, 2019.
39. Huang X,Zhou X,Hu Q, Sun B, Deng M, Qi X and Lü M: Advances in esophageal cancer: A new perspective on pathogenesis associated with long non-coding RNAs. Cancer Lett 413: 94-101, 2018.

40. Szklarczyk D, Morris JH, Cook H, Kuhn M, Wyder S, Simonovic M, Santos A, Doncheva NT, Roth A, Bork P, et al: The STRING database in 2017: Quality-controlled protein-protein association networks, made broadly accessible. Nucleic Acids Res 45 (D1): D362-D368, 2017.

41. Wang Y, Shi L, Li J, Wang Hand Yang H: The roles of TG-interacting factor in cadmium exposure-promoted invasion and migration of lung cancer cells. Toxicol In Vitro 61: 104630, 2019.

42. Zhang LN, Zhao L, Yan XL and Huang YH: Loss of G3BP1 suppresses proliferation, migration, and invasion of esophageal cancer cells via Wnt/ $\beta$-catenin and PI3K/AKT signaling pathways. J Cell Physiol 234: 20469-20484, 2019.

43. Yu F, Yu C, Li F, Zuo Y, Wang Y, Yao L, Wu C, Wang C and Ye L: Wnt/ $\beta$-catenin signaling in cancers and targeted therapies. Signal Transduct Target Ther 6: 307, 2021.

This work is licensed under a Creative Commons Attribution-NonCommercial-NoDerivatives 4.0 International (CC BY-NC-ND 4.0) License. 